\title{
Ocular Growth and Refractive Status Development in Premature Infants Conceived by In Vitro Fertilization or Natural Conception
}

Jimeng Lao

Wenzhou Medical University Eye Hospital

Jianbo Mao

Wenzhou Medical University Eye Hospital

Chenyi Liu

Midwestern University

Xueting Yu

Wenzhou Medical University Eye Hospital

Yirun Shao

Wenzhou Medical University Eye Hospital

Caiyun Zhang

Wenzhou Medical University Eye Hospital

Hanxiao Li

Wenzhou Medical University Eye Hospital

Lijun Shen ( $\boldsymbol{\sigma}$ slj@mail.eye.ac.cn )

The Affiliated Eye Hospital of Wenzhou Medical University

Research article

Keywords: Ocular Growth, Refractive Status, Premature Infants, In Vitro Fertilization, Natural Conception

Posted Date: December 17th, 2019

DOI: https://doi.org/10.21203/rs.2.18973/v1

License: (c) (i) This work is licensed under a Creative Commons Attribution 4.0 International License.

Read Full License 


\section{Abstract}

Background: To evaluate the effects of IVF on the development of the refractive system in premature infants from 36 weeks to 6 months of postmenstrual age. Methods: Premature infants were examined respectively at 36 weeks, 40 weeks, 44 weeks, 48 weeks, 52 weeks and 6 months of postmenstrual age. Spherical equivalent, biometric values and central corneal thickness were measured. These parameters were compared between premature infants conceived by IVF or naturally, and the relationship between these parameters were evaluated. Results: A total of 899 premature infants were recruited. Infants born by IVF had a higher rate of oxygen therapy than which in the NC group $(P=0.04)$. The multiple pregnancy ratio in the IVF group was $83.4 \%$, significantly higher than which in the NC group $(p<0.001)$. ROP developed in 126 of the 754 infants (16.7\%) in the NC group and in 35 of the 145 (24.1\%) infants in the IVF group ( $p=0.03)$. With the increase of PA, the ACD $(r=0.67, p<0.0001), L T(r=0.19, p<0.0001), V T(r=0.80$, $p<0.0001)$ and $A L(r=0.85, p<0.0001)$ increased while CCT $(r=-0.39, p<0.0001)$ thinned. The refractive state had a hyperopic shift until 44 weeks of postmenstrual age $(r=0.38, p<0.0001)$. then the mean dioptric value continuously declined by 6 months of PA $(r=-0.32, p<0.0001)$. There was no statistically significant difference in these parameters between the NC group and IVF group ( $p>0.05)$. The percentage of ACD $(r=0.326, p<0.0001)$ and VT $(r=0.248, p<0.0001)$ in AL were positively correlated with PA, while the percentage of LT $(r=-0.415, p<0.0001)$ in AL was negatively correlated with PA. Before 44 weeks of PA, SE was positively correlated with $A C D(r=0.08, p<0.01)$ and $A L(r=0.09, p<0.01)$. After 44 weeks of PA, it was negatively correlated with ACD $(r=-0.23, p<0.0001)$, VT $(r=-0.35, p<0.0001)$ and $A L(r=-0.41, p<0.01)$. Conclusions: The percentage of ACD and VT in AL increased, the percentage of $L T$ in AL decreased with the early ocular development. IVF does not affect ocular growth from 36 weeks to 6 months of PA.

\section{Background}

Since the birth of the first "test tube baby" in 1978, more and more children have been born with the help of reproductive technology. The in vitro fertilization (IVF) pregnancies were associated with high birth prevalence of congenital malformations and had a high risk of preterm delivery [1]. Studies have found that children born by IVF have higher rates of retinoblastoma and ocular anomalies [2,3].

Some scholars have focused on whether the IVF would have an influence on refractive system $[4,5]$. Ruth Axer-Siegel [4] observed 133 premature infants, which were split into four subgroups according to postmenstrual age (PA) at examination ( $<32$ weeks, 33-36 weeks, 37-41 weeks, and > 41 weeks), and found IVF apparently did not affect early ocular growth, intraocular pressure, changes in corneal curvature, or retinal vascularization in premature infants. However, refractive index and corneal thickness were not included in their study. In addition, we were concerned that the effects hadn't shown up in the early days.

The purpose of the present study was to evaluate the effects of IVF on the development of the refractive system in premature infants from 36 weeks to 6 months of PA, including anterior chamber depth (ACD), lens thickness (LT), vitreous thickness (VT), axial length (AL), central corneal thickness (CCT) and spherical equivalent (SE). 


\section{Methods}

A total of 899 premature infants who were screened at the hospital for retinopathy of prematurity (ROP) participated in this study. The exam was performed at the Eye Hospital of Wenzhou Medical University from January 2016 to May 2018. Ethics approval and consent to participate were obtained. All methodologies adhered to the tenets of the Declaration of Helsinki. Infants with poor physical condition leading to intolerance of examination, infectious disease, and refractive interstitial opacity such as congenital cataracts were excluded from this study.

The eye examinations were performed respectively at 36 weeks, 40 weeks, 44 weeks, 48 weeks, 52 weeks and 6 months of postmenstrual age. All examinations were performed by the same examiner respectively on the right eyes.

$1 \mathrm{drop}$ of $5 \mathrm{mg} / \mathrm{ml}$ tropicamide was instilled three times in each eye at an intervals of 10 minutes. 30 minutes later, full cycloplegic retinoscopy was performed using a streak retinoscope (66 Vision Technology, Suzhou, Jiangsu Province, China). Eyelids were held open with a pediatric speculum after topical anesthesia. Refractive error was recorded in the form of SE, where the SE = sphere + cylinder $/ 2$.

Biometry was measured with an A-scan biometer (Quantel Axis Nano, Cournon d' Auvergne Cedex, France). The probe was placed gently on the center of the cornea, perpendicular to its axis until at least three clear traces were obtained on the screen. The average value was recorded for all ocular biometry parameters including ACD, LT, VT and AL.

Central corneal thickness (CCT) was measured by a hand-held corneal pachymeter (PachPen, Accutome, USA). The probe was placed vertically into the center of the cornea until three readings were obtained. The average value was recorded for each eye.

The basic information, including gender, birth weight (BW), gestational age (GA), postmenstrual age (PA) at each examine, type of pregnancy (singleton/multiple), type of fertilization (IVF / natural conception (NC)), the history of oxygen and presence of ROP were recorded.

Statistical analysis was performed using the Statistical Package for Social Sciences (SPSS version 19.0, SPSS, Inc., Chicago, IL, USA). The results were recorded as the means \pm standard deviations (SD). Independent samples t-tests were used to evaluate the difference in GA, BW, and refractive system parameters (SE, ACD, LT, VT, AL and CCT) between IVF and NC at each postmenstrual age. Chi-square tests were used to compare the difference in gender, type of pregnancy, the history of oxygen and presence of ROP between two groups. Correlation analysis were used to analyze the correlation between these various parameters. Significance was defined as $\mathrm{P}<0.05$.

\section{Results}

A total of 899 premature infants were recruited in this study. There were 754 (83.9\%) infants born naturally, and 145 infants (16.1\%) conceived by IVF. The mean BW in the NC group was $1540 \pm 14.38 \mathrm{~g}$; in the IVF 
group was $1430 \pm 32.56 \mathrm{~g}$. The mean GA in the NC group was $30.7 \pm 0.08$ weeks; in the IVF group was $30.1 \pm 0.19$ weeks. There was significant difference between the two groups both in BW and GA $(t=3.01$; $2.86, \mathrm{P}=0.003 ; 0.004)$ (Table 1$)$.

There were 403 boys and 351 girls in the NC group, 88 boys and 57 girls in the IVF group. There was no statistically significant difference ( $p>0.05) .101$ infants $(69.7 \%)$ in the IVF group and 456 infants $(61.2 \%)$ in the NC group received oxygen therapy. Infants born by IVF had a higher rate of oxygen therapy than which in the NC group, and the difference was statistically significant $(P=0.04)$. The multiple pregnancy ratio in the IVF group was $83.4 \%$, significantly higher than which in the NC group $(p<0.001)$. ROP developed in 126 of the 754 infants (16.7\%) in the NC group and in 35 of the 145 (24.1\%) infants in the IVF group. The incidence of ROP was higher in IVF group than in NC group $(p=0.03)$ (Table 1).

Table 2 showed the changes of refractive system parameters at each follow-up. With the increase of PA, the ACD $(r=0.67, p<0.0001)$, LT $(r=0.19, p<0.0001)$, VT $(r=0.80, p<0.0001)$ and AL $(r=0.85, p<0.0001)$ increased gradually (Fig. 1). CCT ( $r=-0.39, p<0.0001)$ gradually thinned with the increase of PA (Fig. 2). The refractive state had a hyperopic shift until 44 weeks of postmenstrual age $(r=0.38, p<0.0001)$. After that, the mean dioptric value continuously declined by 6 months of PA $(r=-0.32, p<0.0001)$ (Fig. 3). There was no statistically significant difference in these parameters between the NC group and IVF group ( $p>$ 0.05).

AL was positively correlated with ACD $(r=0.67, p<0.0001)$, LT $(r=0.30, p<0.0001)$ and VT $(r=0.90, p<$ $0.0001)$, while negatively correlated with CCT $(r=-0.35, p<0.0001)$. CCT was negatively correlated with ACD $(r=-0.22, p<0.0001)$ and VT $(r=-0.38, p<0.0001)$, however CCT was not correlated with LT $(r=-0.04, p>$ $0.05)$.

The percentage of ACD $(r=0.326, p<0.0001)$ and VT $(r=0.248, p<0.0001)$ in AL were positively correlated with PA, while the percentage of $L T(r=-0.415, p<0.0001)$ in AL was negatively correlated with PA (Table 3$)$.

As for SE, before 44 weeks of PA, it was positively correlated with ACD $(r=0.08, p<0.01)$ and AL $(r=0.09$, $p<0.01)$. After 44 weeks of PA, it was negatively correlated with ACD $(r=-0.23, p<0.0001), V T(r=-0.35, p<$ $0.0001)$ and $A L(r=-0.41, p<0.01)$.

\section{Discussion}

More than 40 years have passed since the first baby was born by IVF [6]. A systematic review and meta-analysis found pregnancies generated by IVF experienced higher birth prevalence for congenital malformations, such as cleft lip and/or palate, eye, ear, face and neck, chromosomal, respiratory, digestive, musculoskeletal, urogenital, and circulatory system malformations [1]. The infants born by IVF have been associated with a high risk of preterm delivery, multiple gestation, low birth weight and low GA [7]. In this study, there has been a similar conclusion. Nevertheless, it is still controversial whether IVF has an influence on ROP. Some scholars believed that the IVF technology would lead to a higher proportion of multiple gestation, which was an independent risk factor for the development of ROP [8-10], while others 
reported that there was no significant difference in ROP between NC and IVF [11-13]. In the present study, ROP developed in 126 of the 754 infants (16.7\%) in the NC group and in 35 of the $145(24.1 \%)$ infants in the IVF group. However, since the IVF group had a lower birth weight, we could not be sure about that IVF was an independent risk factor for the development of ROP.

Anteby [3] studied 47 children conceived by IVF and found ocular malformations in 12 (26\%), including coats' disease, congenital cataract, coloboma of the uvea, hypoplastic optic nerve heads, idiopathic optic atrophy, congenital glaucoma, and retinoblastoma. Ruth Axer-Siegel $[4,5]$ evaluated

the effects of IVF on the early development of the eye both in premature infants and full-term healthy infants and found IVF apparently does not affect early ocular growth. We were concerned that the effects hadn't shown up in the early days, so we did research from 36 weeks to 6 months of PA. We also found no statistical differences in comparison.

In this present study, SE had a hyperopic shift until 44 weeks of postmenstrual age. After that, the mean dioptric value gradually and continuously declined by 6 months of PA. at 6 months of PA, the SE was + $2.00 \pm 0.17 \mathrm{D}$ in NC group and $+2.08 \pm 0.23 \mathrm{D}$ in IVF group. Uprety $S$ [14] found the $S E$ in the pre-term infants was $+0.84 \pm 1.72 \mathrm{D}$ at birth, however, there was a shift toward myopia at 6 months of age (SE = $-0.33 \pm 1.95 \mathrm{D})$, which was quite different from ours. Shu-Juan Yu [15] studied the evolution of the refractive status in a large sample size in China and found the refractive state reached the top $(+2.43 \pm$ $1.46 \mathrm{D}$ ) at the age of one to two months. At 5-6 months of PA, the SE was +1.87 $\pm 1.58 \mathrm{D}$. Ton [16] referred that the mean SE of infants was +1.24 D in infants aged 1 month or less and reached to $+2.50 \mathrm{D}$ at the age of 4-6month, which was similar to ours.

The CCT of preterm infants decreased from $592.5 \pm 2.5 \mu \mathrm{m}$ to $528.2 \pm 4.6 \mu \mathrm{m}$ in NC group, $598.5 \pm 5.5 \mu \mathrm{m}$ to $520.7 \pm 4.6 \mu \mathrm{m}$ in IVF group at the end of follow-up in this study. In Jitendra Jethani' s study [17], the CCT decreased from the mean value of $620.7 \pm 88.8 \mu \mathrm{m}$ to $578.3 \pm 79.6 \mu \mathrm{m}$ at the end of 8 weeks. At the end of 20 weeks, it was $558.4 \pm 52.4 \mu \mathrm{m}$ which further reduced to $534.1 \pm 57.6 \mu \mathrm{m}$ at the end of 1 -year. Autzen [18] reported CCT values of $654 \pm 84 \mu \mathrm{m}$ at 20 days and $566 \pm 64 \mu \mathrm{m}$ at 110 days. Kirwan [19] studied 35 premature infants and found the CCT was $691 \pm 87,648 \pm 72,605 \pm 59$ and $564 \pm 34 \mu \mathrm{m}$ at $30-$ $32,34-35,37-38$, and 39-41 weeks of PA, respectively. De Silva [20] showed a gradual decrease in the CCT from $794 \pm 34 \mu \mathrm{m}$ at 28 weeks of PA to $559 \pm 13 \mu \mathrm{m}$ at 42 weeks of PA. CCT gradually thinned with the increase of PA.

With the increase of PA, the ACD, LT, VT and AL increased gradually. This finding was similar to previous ones [21-23]. Anne Cook [21] studied AL, ACD and LT from 136 premature infants between 32 and 52 weeks' PA. The AL increased from $15.4 \mathrm{~mm}$ to $18.6 \mathrm{~mm}$. The $L T$ increased from $3.8 \mathrm{~mm}$ to $4.0 \mathrm{~mm}$. The $A C D$ increased from $2.0 \mathrm{~mm}$ to $2.8 \mathrm{~mm}$. Compared to our study, the AL values were very close. $L T$ changed very little relative to $A L$ as a whole.

\section{Conclusions}


In summary, SE had a hyperopic shift until 44 weeks of postmenstrual age. After that, the mean dioptric value declined by 6 months of PA. With the increase of PA, the ACD, LT, VT and AL increased gradually, CCT gradually decreased. In addition, the percentage of ACD and VT in AL increased, the percentage of LT in AL decreased with the early ocular development. IVF does not affect ocular growth from 36 weeks to 6 months of PA.

\section{List Of Abbreviations}

in vitro fertilization (IVF)

postmenstrual age (PA)

anterior chamber depth (ACD)

lens thickness (LT)

vitreous thickness (VT)

axial length $(A L)$

central corneal thickness (CCT)

spherical equivalent (SE)

retinopathy of prematurity $(\mathrm{ROP})$

birth weight (BW)

gestational age (GA)

natural conception (NC)

\section{Declarations}

\section{Ethics approval and consent to participate}

This study followed the tenets of the Declaration of Helsinki. Local ethical approval was obtained from the ethics committee of the Affiliated Eye Hospital of Wenzhou Medical University, Zhejiang, China. Consent to participate was collected from the parents. Since premature infants were hospitalized in ICU early after birth without their parents, we contacted the parents by telephone to inform them of the study and obtained their verbal consent. The ethics committee approved this procedure.

\section{Consent for publication}

Not applicable. 
Availability of data and materials

The datasets used and/or analyzed during the current study are available from the corresponding author on reasonable request.

\section{Competing interests}

The authors declare that they have no competing interests.

\section{Funding}

This work were supported by the Medical Health Science and Technology Project of Zhejiang Provincial Health Commission [2019PY010], the Basic Scientific Project of Wenzhou Science and Technology Commission [Y20180713] and the National Natural Science Foundation of China [81700884]. Funding body were not involved in the design of the study and collection, analysis, and interpretation of data and in writing the manuscript.

\section{Authors' contributions}

LS supported and monitored the research; JL and JM designed the research; JL and JM analyzed the data and write the paper; $C L$ revised the paper; $X Y, Y S, C Z$ and $H L$ collected data.

\section{Acknowledgements}

Not applicable.

\section{References}

1. Chen L, Yang T, Zheng Z, Yu H, Wang H, Qin J. Birth prevalence of congenital malformations in singleton pregnancies resulting from in vitro fertilization/intracytoplasmic sperm injection worldwide: a systematic review and meta-analysis. Arch Gynecol Obstet. 2018;297(5):1115-1130.

2. Moll AC, Imhof SM, Cruysberg JR, Schouten-van Meeteren AY, Boers M, van Leeuwen FE. In-vitro fertilization and retinoblastoma. Lancet. 2003;361:309-310.

3. Anteby I, Cohen E, Anteby E, Ben Ezra D. Ocular manifestations in children born after in vitro fertilization. Arch Ophthalmol. 2001;119:1525-1529.

4. Axer-Siegel R, Bourla D, Sirota L, Weinberger D, Snir M. Ocular growth in premature infants conceived by in vitro fertilization versus natural conception. Invest Ophthalmol Vis Sci. 2005;46:1163-1169.

5. Axer-Siegel R, Herscovici Z, Davidson S, Linder N, Sherf I, Snir M. Early structural status of the eyes of healthy term neonates conceived by in vitro fertilization or conceived naturally. Invest Ophthalmol Vis Sci. 2007;48(12):5454-8.

6. Steptoe PC, Edwards RG. Birth after the reimplantation of a human embryo. Lancet. 1978;2:366. 
7. Bergh T, Ericson A, Hillensjö T, Nygren KG, Wennerholm UB. Deliveries and children born after in-vitro fertilisation in Sweden 1982-95: a retrospective cohort study. Lancet. 1999;354:1579-1585.

8. Watts $P$, Adams GGW. In vitro fertilisation and stage 3 retinopathy of prematurity. Eye. 2000;15:363364.

9. Sabzehei MK, Afjeh SA, Dastjani FA, Shamshiri AR, Esmaili F. Retinopathy of prematurity: incidence, risk factors, and outcome. Archives of Iranian Medicine. 2013;16:507-512.

10. Mm DSM, Fortes Filho JB, Coblentz J, Fiorot CA. Multiple pregnancies and its relationship with the development of retinopathy of prematurity (ROP). Clinical Ophthalmology. 2011;5:1783-1787.

11. Blumenfeld LC, Siatkowski RM, Johnson RA, Feuer WJ, Flynn JT. Retinopathy of prematurity in multiple-gestation pregnancies. American Journal of Ophthalmology. 1998;125:197-203

12. Friling R, Axer-Siegel R, Hersocovici Z, Weinberger D, Sirota L, Snir M. Retinopathy of Prematurity in Assisted versus Natural Conception and Singleton versus Multiple Births. Ophthalmology. 2007;114:321-324.

13. Barker L, Bunce $C$, Husain S, Adams GG. Is artificial reproductive technology a risk factor for retinopathy of prematurity independent of the generation of multiple births? European Journal of Ophthalmology. 2017;27(2):174-178.

14. Uprety S, Morjaria P, Shrestha JB, Shrestha GS, Khanal S. Refractive Status in Nepalese Pre-Term and Full-Term Infants Early in Life. Optom Vis Sci. 2017;94(10):957-964.

15. Yu SJ, Liu GH, Liu Y, et al. The evolution of refractive status in Chinese infants during the first year of life and its affected factors. Int J Ophthalmol. 2017;10:1290-1294.

16. Ton Y, Wysenbeek YS, Spierer A. Refractive error in premature infants. J AAPOS. 2004;8(6):534-538.

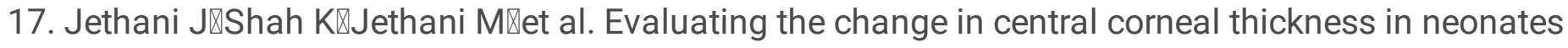
(term and preterm) in Indian population and the factors affecting it[J]. Indian Journal of Ophthalmology. 2015,63(6):501-503.

18. Autzen T, Bjørnstrøm L. Central corneal thickness in premature babies. Acta Ophthalmol (Copenh). 1991;69:251-2.

19. Kirwan C, O'Keefe M, Fitzsimon S. Central corneal thickness and corneal diameter in premature infants. Acta Ophthalmol Scand. 2005;83:751-3.

20. De Silva S, Parentin F, Michieletto P, Pensiero S. Corneal curvature and thickness development in premature infants. J Pediatr Ophthalmol Strabismus. 2011;48:25-9

21. Cook A, White S, Batterbury M, Clark D. Ocular growth and refractive error development in premature infants with or without retinopathy of prematurity. Invest Ophthalmol Vis Sci. 2008;49:5199-5207.

22. Özdemir Ö, ÖzenTunay Z, ErgintürkAcar D. Growth of biometric components and development of refractive errors in premature infants with or without retinopathy of prematurity. Turk J Med Sci. 2016;46:468-473.

23. Özdemir Ö, ÖzenTunay Z, ErgintürkAcar D, Sener E, Acar U. The relationship of birth weight, gestational age, and postmenstrual age with ocular biometry parameters in premature infants. Arq Bras Oftalmol. 2015;78(3):146-149. 


\section{Tables}

Table1. Basic information

\begin{tabular}{ccccc}
\hline & NC $(\mathrm{n}=754)$ & IVF $(\mathrm{n}=145)$ & t/chi-square & $\mathrm{p}$ \\
\hline GA (weeks) & $30.7 \pm 0.08$ & $30.1 \pm 0.19$ & 2.861 & $0.004^{*}$ \\
BW (g) & $1540 \pm 14.38$ & $1430 \pm 32.56$ & 3.007 & $0.003^{*}$ \\
Gender(male/female) & $403 / 351$ & $88 / 57$ & 2.573 & 0.11 \\
oxygen uptake & $456(61.2 \%)$ & $101(69.7 \%)$ & 4.346 & $0.04^{*}$ \\
multiplets & $233(30.9 \%)$ & $121(83.4 \%)$ & 140.7 & $<0.0001^{*}$ \\
ROP & $126(16.7 \%)$ & $35(24.1 \%)$ & 4.563 & $0.03^{*}$ \\
\hline
\end{tabular}

IVF, in vitro fertilization; NC, natural conception; BW, birth weight; GA, gestational age; ROP, retinopathy of prematurity 
Table 2. Changes of refractive system parameters with PA

\begin{tabular}{|c|c|c|c|c|c|c|}
\hline $\begin{array}{l}\text { 36weeks } \\
\mathrm{n}(\mathrm{NC} / \mathrm{IVF})\end{array}$ & $\begin{array}{l}\text { 40weeks } \\
528 / 122\end{array}$ & $\begin{array}{l}\text { 44weeks } \\
408 / 74\end{array}$ & $\begin{array}{l}\text { 48weeks } \\
172 / 39 \\
\end{array}$ & $\begin{array}{l}\text { 52weeks } \\
113 / 45\end{array}$ & $\begin{array}{l}\text { 6months } \\
79 / 51\end{array}$ & $83 / 45$ \\
\hline \multicolumn{7}{|l|}{$\mathrm{ACD}(\mathrm{mm})$} \\
\hline Total & $2.00 \pm 0.20$ & $2.09 \pm 0.20$ & $2.19 \pm 0.21$ & $2.32 \pm 0.26$ & $2.45 \pm 0.29$ & $2.77 \pm 0.34$ \\
\hline $\mathrm{NC}$ & $2.01 \pm 0.20$ & $2.09 \pm 0.21$ & $2.18 \pm 0.21$ & $2.33 \pm 0.27$ & $2.43 \pm 0.27$ & $2.81 \pm 0.33$ \\
\hline IVF & $1.98 \pm 0.20$ & $2.07 \pm 0.18$ & $2.23 \pm 0.19$ & $2.29 \pm 0.22$ & $2.49 \pm 0.32$ & $2.71 \pm 0.35$ \\
\hline $\mathrm{P}$ & 0.09 & 0.40 & 0.19 & 0.38 & 0.27 & 0.14 \\
\hline \multicolumn{7}{|l|}{$\mathrm{LT}(\mathrm{mm})$} \\
\hline Total & $4.09 \pm 0.36$ & $4.18 \pm 0.31$ & $4.21 \pm 0.37$ & $4.28 \pm 0.36$ & $4.29 \pm 0.34$ & $4.26 \pm 0.44$ \\
\hline NC & $4.09 \pm 0.37$ & $4.18 \pm 0.32$ & $4.22 \pm 0.37$ & $4.27 \pm 0.33$ & $4.28 \pm 0.35$ & $4.22 \pm 0.43$ \\
\hline IVF & $4.09 \pm 0.31$ & $4.18 \pm 0.29$ & $4.17 \pm 0.36$ & $4.31 \pm 0.43$ & $4.29 \pm 0.33$ & $4.33 \pm 0.45$ \\
\hline $\mathrm{P}$ & 0.91 & 0.99 & 0.45 & 0.50 & 0.98 & 0.20 \\
\hline \multicolumn{7}{|l|}{$\mathrm{VT}(\mathrm{mm})$} \\
\hline Total & $10.34 \pm 0.47$ & $10.89 \pm 0.46$ & $11.29 \pm 0.66$ & $11.60 \pm 0.45$ & $11.97 \pm 0.52$ & $12.83 \pm 0.62$ \\
\hline NC & $10.34 \pm 0.49$ & $10.88 \pm 0.45$ & $11.30 \pm 0.69$ & $11.57 \pm 0.49$ & $11.94 \pm 0.61$ & $12.82 \pm 0.57$ \\
\hline IVF & $10.32 \pm 0.42$ & $10.93 \pm 0.47$ & $11.26 \pm 0.50$ & $11.67 \pm 0.33$ & $12.01 \pm 0.35$ & $12.84 \pm 0.70$ \\
\hline $\mathrm{P}$ & 0.71 & 0.37 & 0.75 & 0.22 & 0.49 & 0.91 \\
\hline
\end{tabular}

$\mathrm{AL}(\mathrm{mm})$

\begin{tabular}{lllllll} 
Total & $16.41 \pm 0.62$ & $17.15 \pm 0.52$ & $17.64 \pm 0.54$ & $18.20 \pm 0.55$ & $18.70 \pm 0.57$ & $19.86 \pm 0.78$ \\
\hline NC & $16.42 \pm 0.65$ & $17.15 \pm 0.52$ & $17.64 \pm 0.54$ & $18.18 \pm 0.55$ & $18.65 \pm 0.60$ & $19.85 \pm 0.73$ \\
\hline IVF & $16.38 \pm 0.50$ & $17.17 \pm 0.53$ & $17.65 \pm 0.57$ & $18.27 \pm 0.56$ & $18.78 \pm 0.53$ & $19.87 \pm 0.87$ \\
\hline P & 0.47 & 0.72 & 0.89 & 0.34 & 0.19 & 0.85
\end{tabular}

CCT $(\mu \mathrm{m})$

Total

NC

$593.6 \pm 54.4 \quad 562.1 \pm 52.0$

$547.2 \pm 47.1$

$534.1 \pm 38.2$

$529.5 \pm 33.9 \quad 528.0 \pm 34.6$

IVF $592.5 \pm 55.5 \quad 562.5 \pm 53.4$

$547.3 \pm 48.6$

$535.2 \pm 40.9$

$527.3 \pm 39.1528 .2 \pm 37.1$

$\mathrm{P}$ $598.5 \pm 49.5$

$560.1 \pm 43.8$

$546.7 \pm 40.5$

$531.0 \pm 29.9$

$532.4 \pm 25.6$

$527.6 \pm 30.0$

SE (D)

\begin{tabular}{lllllll} 
Total & $1.24 \pm 2.09$ & $2.86 \pm 1.78$ & $3.51 \pm 1.65$ & $3.34 \pm 1.49$ & $3.11 \pm 1.51$ & $2.03 \pm 1.54$ \\
\hline NC & $1.23 \pm 1.31$ & $2.86 \pm 1.80$ & $3.51 \pm 1.65$ & $3.38 \pm 1.59$ & $3.10 \pm 1.74$ & $2.00 \pm 1.56$ \\
\hline IVF & $1.31 \pm 1.85$ & $2.85 \pm 1.63$ & $3.48 \pm 1.67$ & $3.24 \pm 1.25$ & $3.12 \pm 1.07$ & $2.08 \pm 1.54$ \\
\hline P & 0.68 & 0.10 & 0.92 & 0.58 & 0.94 & 0.78 \\
\hline
\end{tabular}

PA, postmenstrual age; IVF, in vitro fertilization; NC, natural conception; ACD, anterior chamber depth; LT, lens thickness; VT, vitreous thickness; AL, axial length, CCT, central corneal thickness; SE, spherical equivalent 
Table 3. The percentage of ACD, LT and VT in AL (\%)

\begin{tabular}{ccccccccc}
\hline PA & 36weeks & 40weeks & 44weeks & 48weeks & 52weeks & 6 months & $\mathrm{r}$ & $\mathrm{p}$ \\
\hline ACD & 12.19 & 12.13 & 12.39 & 12.77 & 13.05 & 13.95 & 0.326 & $<0.0001$ \\
& \pm 0.01 & \pm 0.01 & \pm 0.01 & \pm 0.01 & \pm 0.01 & \pm 0.02 & & \\
LT & 24.95 & 24.40 & 23.90 & 23.55 & 22.87 & 21.42 & -0.415 & $<0.0001$ \\
& \pm 0.02 & \pm 0.02 & \pm 0.02 & \pm 0.02 & \pm 0.02 & \pm 0.02 & & \\
VT & 62.87 & 63.46 & 63.71 & 63.70 & 64.08 & 64.64 & 0.248 & $<0.0001$ \\
& \pm 0.02 & \pm 0.02 & \pm 0.02 & \pm 0.02 & \pm 0.02 & \pm 0.01 & & \\
\hline
\end{tabular}

PA, postmenstrual age; ACD, anterior chamber depth; LT, lens thickness; VT, vitreous thickness; AL, axial length

Figures

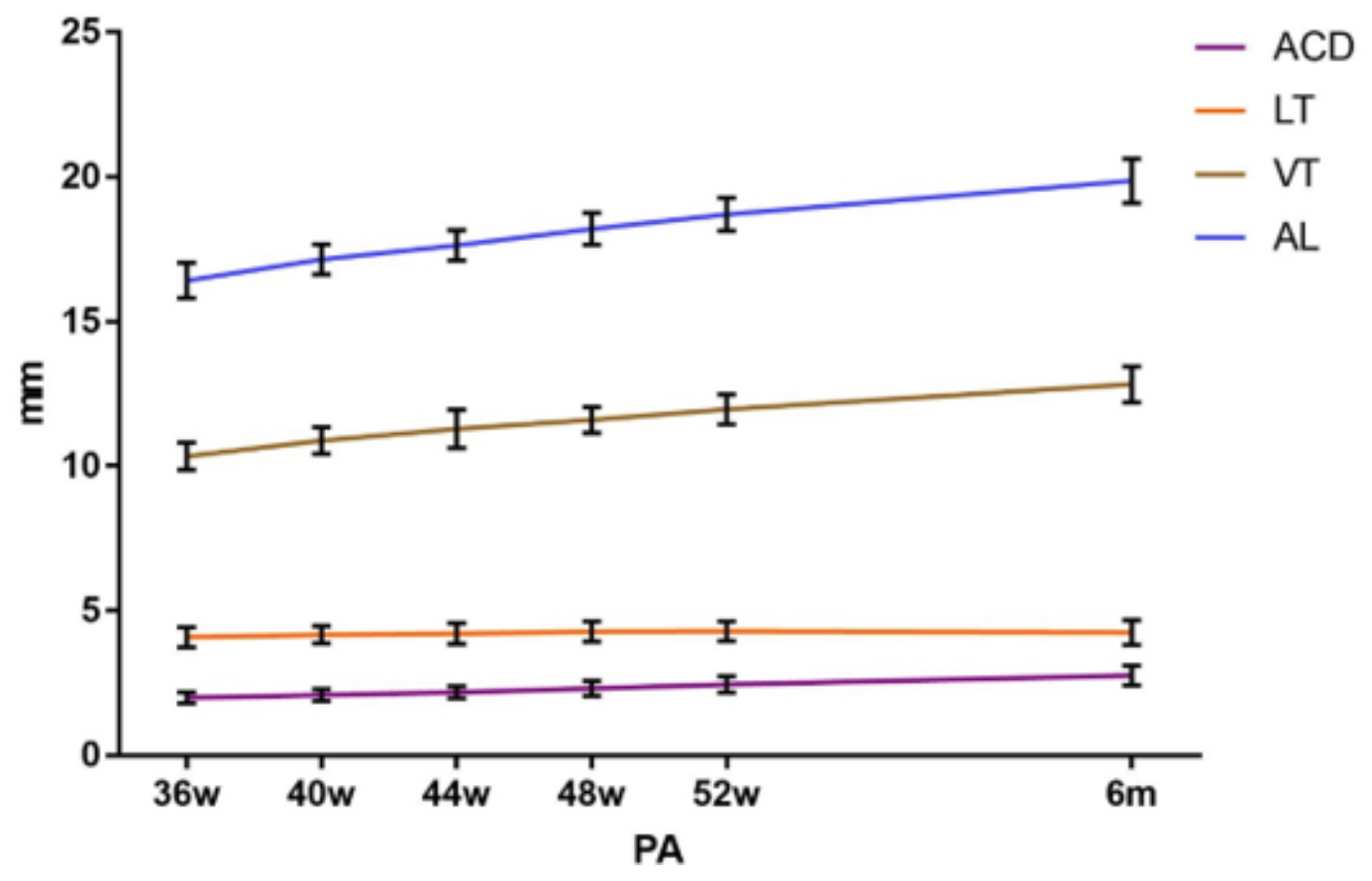

Figure 1

Correlation between ocular biometry parameters and PA. PA, postmenstrual age; ACD, anterior chamber depth; LT, lens thickness; VT, vitreous thickness; AL, axial length. 


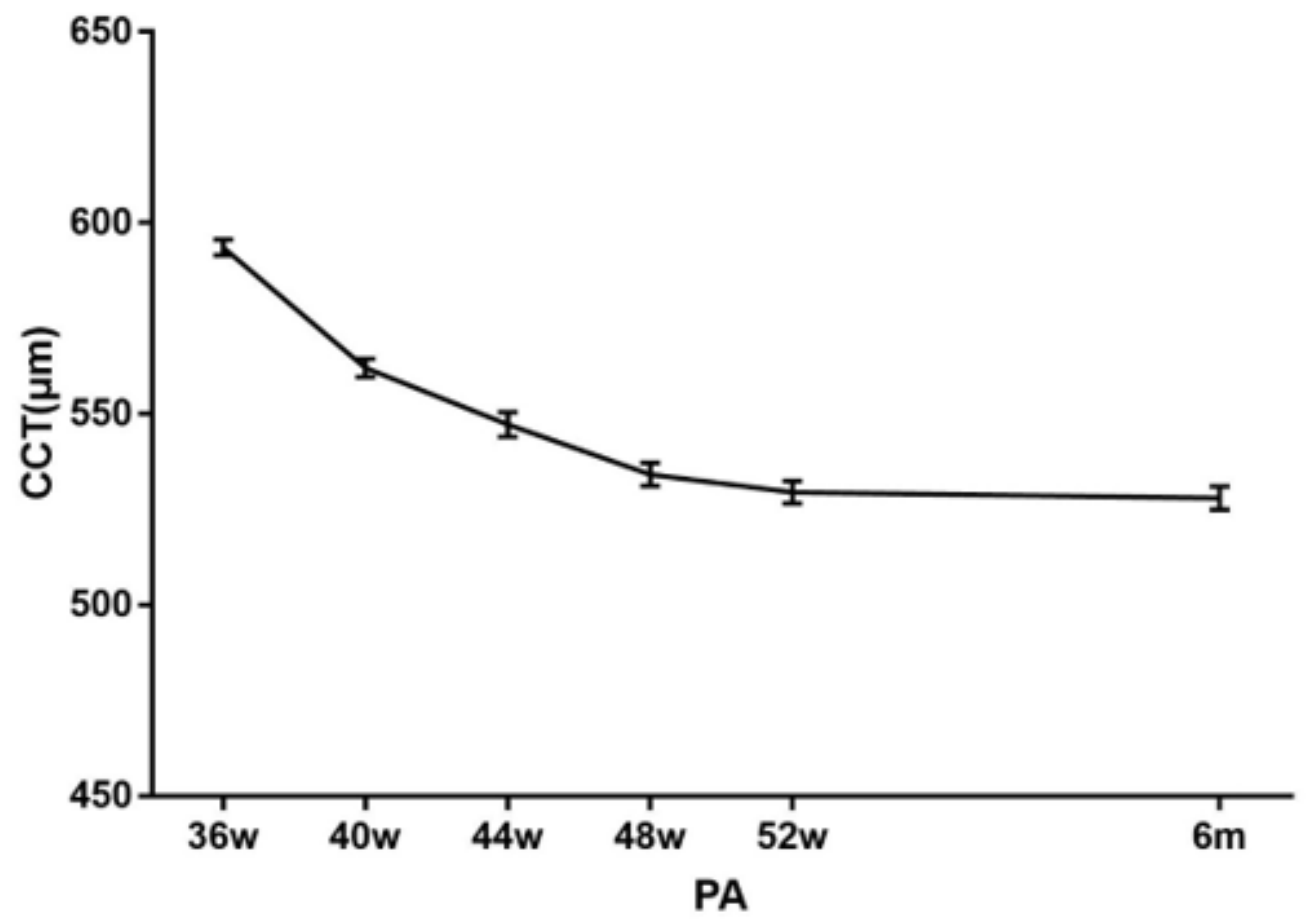

Figure 2

Correlation between CCT and PA. PA, postmenstrual age; CCT, central corneal thickness.

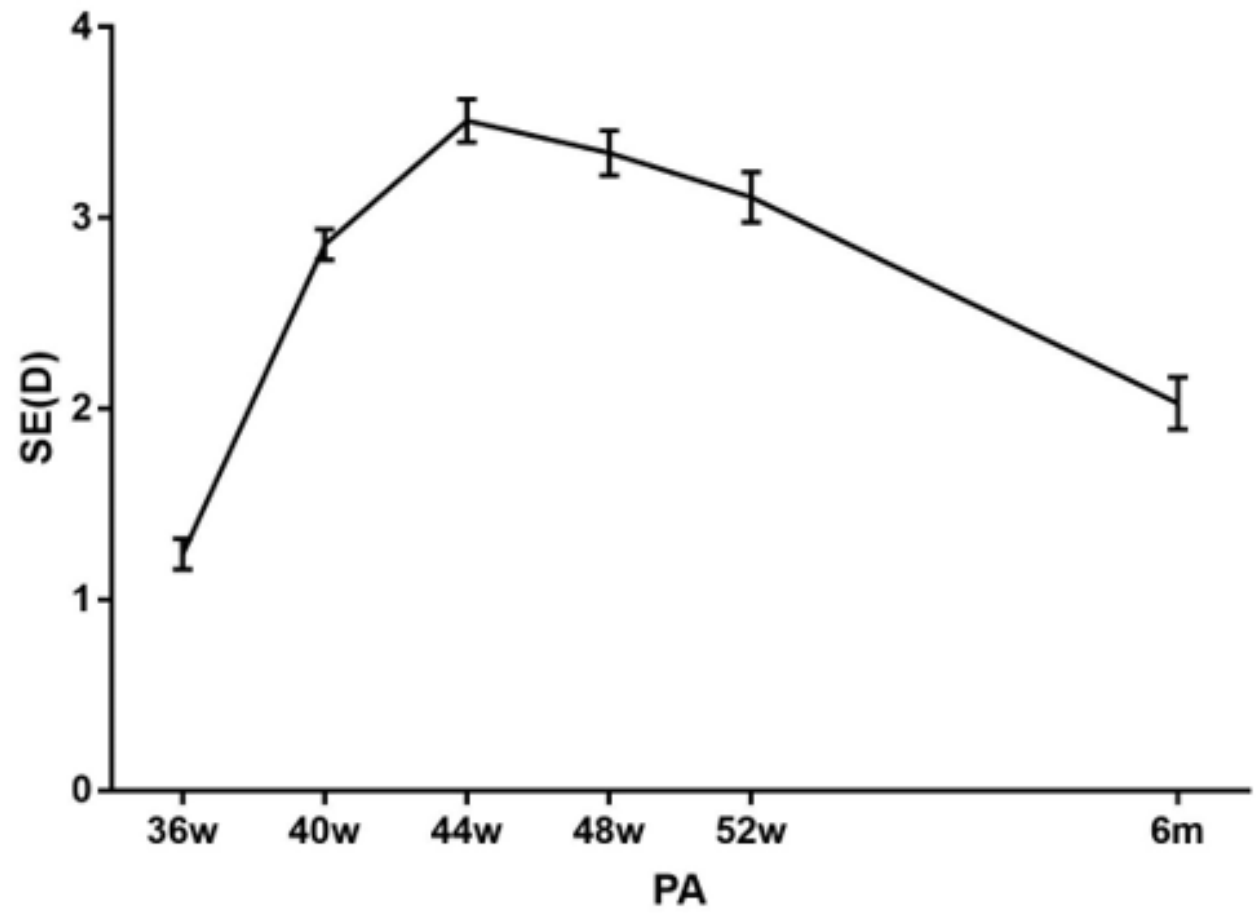

Figure 3

Correlation between SE and PA. PA, postmenstrual age; SE, spherical equivalent; D, diopter. 